\title{
Research on Supply Chain Inventory Management Strategy under Uncertain Demand
}

\author{
Xia Yu \\ Guangdong University of Science \& Technology, Dongguan, Guangdong, 523083, China \\ 151493047@qq.com
}

Keywords: uncertain demand, supply chain, enterprise, inventory management.

\begin{abstract}
The era of new knowledge economy came into being. Under the condition of uncertainty of demand, the control of supply chain inventory has become a major trend in the development of inventory management. However, our country started late in this regard, and there are few studies. Most of them only stay in the theoretical model. In the process of implementing supply chain management, grasping and controlling the uncertainty of supply chain demand is one of the important factors in the success of supply chain management ${ }^{[1]}$. In view of these problems in our country, this article elaborates theories related to supply chain inventory management, and focuses on its current status, problems, and causes. It investigates strategies to reduce the uncertainty of supply chain demand. Its purpose is to achieve supply and demand. Balance, improve the overall supply chain income.
\end{abstract}

\section{Introduction}

With the development of the process of economic globalization and the renewal of modern enterprise management mechanisms, the modern enterprise's procurement, production, and sales models are no longer the simple point and online management models, but a three-dimensional network-like model. It has greater interactivity and requires companies to pay more attention to the speed, flexibility, and accuracy of management work. This has prompted large companies to take the lead in establishing their own supply chain systems [2]. Therefore, under the uncertainty demand, it is very necessary to study the enterprise supply chain inventory management strategy.

\section{Supply Chain}

\subsection{Supply Chain Concept}

The concept of supply chain is developed from the expanded production concept. The definition of supply chain in modern management education is "supply chain is centered on the core enterprise, and through the control of business flow, information flow, logistics and capital flow, starting from the procurement of raw materials. The overall functional network structure formed by suppliers, manufacturers, distributors, retailers, and end-users through the production of intermediate products and final products, and ultimately the products delivered to consumers by the sales network." The effect of the overall supply chain formation is to achieve the supply chain as shown in Figure 1, with a production center as the core, and to send products to other units.

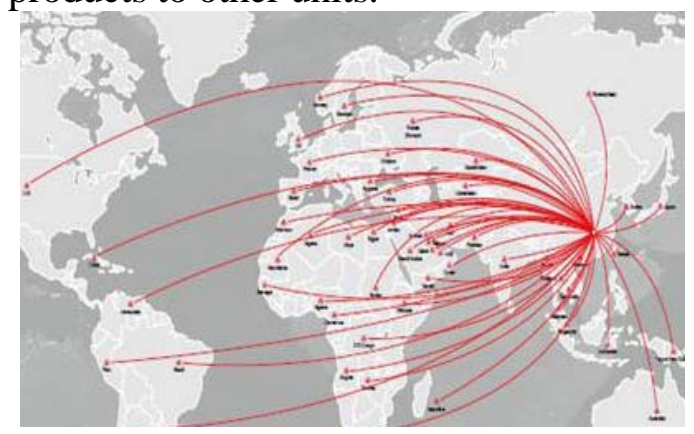

Figure 1 The overall effect of the supply chain 


\subsection{Supply Chain Process}

The supply chain generally includes four processes: material circulation, commercial circulation, information circulation, and capital circulation. The four processes have different functions and different directions of circulation. Figure 2 below is a schematic diagram of the supply chain process.

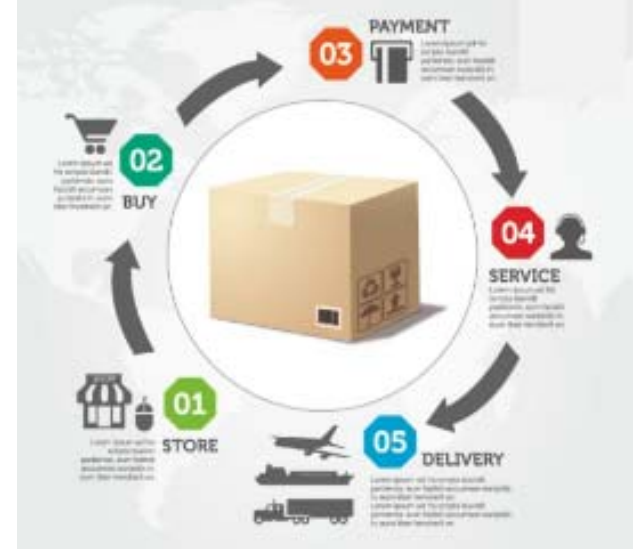

Figure 2 Supply Chain Process

The flow of folding materials is mainly the flow of goods (goods), which is a procedure for sending goods. The direction of the process is directed by the suppliers to the consumers via manufacturers, wholesale and logistics, retailers, and so on. Due to the fact that corporate theories have been developed around the product for a long time, the material flow has been widely considered by people. Many logistics theories involve how to deliver goods at low cost in a short period of time in the process of material circulation [3].

The process of folding commercial circulation is mainly the circulation process of buying and selling. This is the business process of accepting orders and signing contracts. The direction of the process is two-way flow between suppliers and consumers. Commercial circulation tends to be diversified: there are traditional ways of store sales, home sales, and mail-order, and e-commerce forms of shopping through emerging media such as the Internet.

The process of folding information flow is the flow of goods and transaction information. The direction of the process is also two-way flow between suppliers and consumers. In the past, people often focused on the physical items they could see, so information flow has been neglected. Some people even believe that the country's backward logistics is not related to the fact that they have over-invested the funds into material processes and delayed the grasp of information.

The circulation process of the folded capital is the circulation of money. To ensure the normal operation of the enterprise, it is necessary to ensure the timely recovery of funds, otherwise the company cannot establish a perfect operating system. The direction of the process is directed by the consumer to the supplier via retailers, wholesale and logistics and manufacturers.

\section{Research on Supply Chain Inventory Management Strategy under Uncertain Demand}

In the fiercely changing market competition environment, coordination between supply chain companies and

In the process of cooperation, there is a lot of demand uncertainty. As long as there is uncertainty in demand, there are certain risks. Therefore, supply chain managers need to reduce supply chain uncertainty and achieve a balance between supply and demand, thereby increasing the overall supply chain revenue.

\subsection{Improve supply chain forecasting}

In order to better understand their customers, the company strengthens coordination and communication at all stages of the supply chain, uses a demand planning information system, understands market information in a timely manner, organizes production according to market demand, stabilizes sales plans, and improves predictability. In practical applications, companies can determine requirements and plans within a specific time frame. For example, quarterly, monthly, ten-day, or weekly, 
companies should strive to improve the accuracy of recent sales plans, and shorten the length of implementation of plans. To organize production by week or even days, and through the analysis of forecasting and forecasting errors, determine the safety stocks and procurement plans for materials, improve the accuracy of procurement and reduce the inventory level [4]. The increase in forecast accuracy will reduce inventory backlog and inventory shortages and increase the company's profits.

\subsection{Using MRPII/JIT Production Mode}

MRPII (Manufacturing Resource Planning) combines the company's top management with middle management to create a resource plan as the core of the activity, and promotes the operation of the company's management cycle to achieve the most effective enterprise management. The JIT (Just In Time) production method means that "when needed, the desired product can be produced in the required quantity". The kanban method is a simple and effective method in the JIT production method. It is also called subpena card system or card system. The kanban method is required to use a fixed format card between the various processes or between enterprises or between the production company and the supplier as a voucher, and the next link should be designated for supply according to its own rhythm and direction of the reverse production process. The production management mode of MRPII/JIT is to combine MRPII and JIT. The upstream process adopts the MRPII production mode, and the downstream processes are controlled by the JIT production mode through the processing orders. The MRPII production method of the upstream process ensures that the raw materials put into the production line can be processed as quickly as possible to meet the demand, thereby ensuring the rational use of the machine; the JIT production method of the downstream process can prevent excessive raw materials from being put into the production line, thereby contributing to the reduction of the number of work-in-process products. , Reduce supply chain uncertainty and reduce inventory costs.

\subsection{Using Rapid Response Management}

Rapid response refers to a series of measures taken by supply chain managers to reduce the delivery time of restocking goods. When the delivery time of goods is shortened, supply chain managers can improve their forecasting accuracy so that supply and demand can be more closely matched, and supply chain profits can be increased accordingly. The quick response methods mainly include quick response (QR) and effective customer response (ECR) methods. They are brand-new business methods and reflect the business management ideas supported by technology. They respond with the right goods at the right time and at the right place. Customer demand, each node company in the supply chain through the establishment of a good trading partnership, the use of bar code and POS scanning and other information technology, enabling downstream companies to track the sale of various commodities and inventory situation to reduce ordering cycle, implementation of automatic replenishment system, Eliminate unnecessary costs and costs in the supply chain system, reduce supply chain uncertainty and improve customer service.

\subsection{Using Delayed Manufacturing Strategy}

In order to quickly meet the diversified needs of end consumers on the basis of constant costs and reduced risks, companies will often maximize the production process of the same process throughout the production and supply process to achieve economies of scale. The process of forming a differentiated order-to-order production is postponed as much as possible. This mode of production is called delayed manufacturing. In fact, delaying manufacturing delays production and transportation to the last moment. The principle is to delay and obtain more market information and to obtain market information on a more accurate basis so as to effectively avoid or even eliminate supply chain risks [5].

\subsection{Planning the Functions of Each Node Enterprise in the Supply Chain}

Through the implementation of supplier management methods to reduce or eliminate the negative impact of demand uncertainty on the supply chain. Implementation of supplier management inventory, unified management and transfer of inventory by suppliers, suppliers through the establishment of partnerships with users (distributors, wholesalers or retailers), and actively increase the frequency of delivery to users, so that suppliers from the past simple The implementation of the purchase order of the user becomes active to share the responsibility of resupply inventory for the user. While accelerating the speed at which the supplier responds to the user demand, it also enables the user to greatly reduce the 
inventory level, thus eliminating the existence of the uncertainty of demand. Caused by unreasonable resource allocation, low supply chain efficiency and other issues.

\section{Conclusion}

Supply chain management is an advanced management concept. Its advanced nature is reflected in the fact that the customer and the end consumer are the business-oriented ones and meet the ultimate expectations of customers and consumers to produce and supply. Because the supply chain is a network structure, once a certain part of the problem occurs, it is immediately spread to the overall situation. Therefore, in the course of the operation of supply chain management, it is required that all enterprise members collect and feedback market information in a timely and accurate manner. In order to achieve rapid reflection and reduce business losses. To achieve this, supply chain management must have advanced information systems and strong information technology as its support.

\section{References}

[1] Yu Huiqiang. Research on inventory control strategy in supply chain management environment [D]. Chongqing University, 2014.

[2] Tang Qiusheng; Ren Yujian; Wang Yong; Ma Xianting; Demand Uncertainty Two-Channel Dual-Channel Closed-Loop Supply Chain Inventory Optimization Model [J]; Forecast; 2016-04

[3] WEI Jie; SUN Jun-qing; YUAN Xue-mei; Study on the Closed-loop Supply Chain Coordination Based on the Third Party[A]; [C]; 2015

[4] Li Hua, Li Yiqiang, Xu Guohua; Research on Lead Time Model in Supply Chain Distribution [J]; Journal of Industrial Engineering and Engineering Management; 2014-03

[5] JIAN LI, SHOUYANG WANG, T.C. EDWIN CHENG. Analysis of postponement strategy by EPQ-based models with planned backorders [J]. 2008, 5(5). 